\title{
The role of preservatives in the conjunctival toxicity of subconjunctival gentamicin injection
}

\author{
M Pande, F Ghanchi
}

\begin{abstract}
Subconjunctival gentamicin was identified as the cause of conjunctival chemosis and capillary closure in a recent study conducted in this department. The gentamicin preparation used in the study contained preservatives. The current prospective study was set up to investigate the role of preservatives in the conjunctival toxicity of subconjunctival gentamicin. Seventy five patients undergoing cataract surgery were enrolled in the study. They were split into three groups of 25 each. Group A patients were given a subconjunctival injection of a preservative-free aqueous solution of gentamicin at the end of the cataract procedure. Group B patients were given a subconjunctival injection of gentamicin containing sodium metabisulphite and disodium edetate as preservatives at the end of the cataract procedure. Group $\mathbf{C}$ was the control group where patients were not given any subconjunctival injection. The incidence and severity of conjunctival chemosis were observed in the three groups. The difference between groups $A$ and $B$ patients who received preservative-free gentamicin and gentamicin with preservatives respectively was significant $(p<0.02)$.
\end{abstract}

In a recent study conducted in this department subconjunctival gentamicin was identified as the cause of conjunctival capillary closure and chemosis. ${ }^{1}$ Jenkins et al in 1990 reported similar manifestations of conjunctival toxicity of subconjunctival gentamicin. ${ }^{2}$ In both these studies the gentamicin preparation (Cidomycin injectable, Roussel) used contained sodium metabisulphite, methyl hydroxybenzoate, propyl hydroxybenzoate and disodium edetate as preservatives. The role of these preservatives as causative or contributory factors in the conjunctival toxicity of gentamicin is not clear. This prospective study was set up to investigate the role played by preservatives in gentamicin toxicity. The above gentamicin preparation is widely used in the UK for subconjunctival injections but it is not recommended by the manufacturer for this use. The gentamicin preparations used in this study are both manufacturer-recommended preparations for subconjunctival use, one with preservatives and one preservative free.

Ophthalmology, Hull

Royal Infirmary, Hull HÜ3 2JZ

M Pande

F Ghanch

Correspondence to: $M$ Pande.

Accepted for publication 29 August 1991

\section{Patients and methods}

Seventy five eyes of 75 patients admitted for cataract surgery at the Hull Royal Infirmary from 20 December 1990 to 20 March 1991 were enrolled in the study. They had a mean age of
75.41 years with a range of 42 to 93 years. There were 35 male and 40 female patients.

Patients with a history of postoperative conjunctival chemosis, chemical burn, conjunctival trauma, and an abnormal conjunctival examination in the form of scarring or symblepharon were excluded from this study.

All patients were routine waiting list admissions and were sequentially allocated on admission into three groups of 25 each as follows.

\section{GROUP A}

Patients given a subconjunctival injection of 20 mg of gentamicin in $0.5 \mathrm{ml}$ in the lower fornix at the conclusion of their cataract operation. The sterile aqueous injection was prepared from gentamicin sterile powder (Cidomycin sterile powder, Roussel, recommended by manufacturer for subconjunctival use ${ }^{3}$ ) in the hospital pharmacy and contained no preservatives.

\section{GROUP B}

Patients given subconjunctival injection of $20 \mathrm{mg}$ of gentamicin in $0.5 \mathrm{ml}$ (DBL Gentamicin injection, David Bull Laboratories recommended by manufacturer for subconjunctival use as per communication to hospital pharmacy) in the lower fornix at the conclusion of their cataract operation. This preparation contains sodium metabisulphite and disodium edetate as preservatives.

\section{GROUP C}

This was the control group and patients did not receive any subconjunctival injection at the conclusion of their cataract operation.

All patients underwent planned extracapsular cataract surgery under general anaesthesia. The conjunctival sacs were examined 24 hours postoperatively and the presence or absence of chemosis was noted. If present the severity was noted using the following criteria.

Grade 1 - involvement up to $30 \%$ of conjunctival area.

Grade 2 - involvement of $30 \%$ to $50 \%$ of conjunctival area.

Grade 3 - involvement of $50 \%$ to $100 \%$ of conjunctival area.

The observer was unaware of patient group allocation during patient examination.
Results

Table 1 shows the incidence of chemosis in the three study groups; 17 of 25 patients in group A and 24 of 25 patients in group B had chemosis 
Table 1 Incidence of chemosis in the study groups

\begin{tabular}{llcl}
\hline & \multicolumn{4}{l}{ Number of patients $(\%)$} \\
\cline { 2 - 4 } Group & Chemosis & No chemosis & Total \\
\hline A & $17(68 \cdot 00)$ & $8(32 \cdot 00)$ & 25 \\
B & $24(96 \cdot 00)$ & $1(4 \cdot 00)$ & 25 \\
C & $0(0 \cdot 00)$ & $25(100 \cdot 00)$ & 25 \\
\hline
\end{tabular}

Table 2 Severity of chemosis in groups $A$ and $B^{\star}$

\begin{tabular}{lllll}
\hline & \multicolumn{4}{l}{ Number of patients $(\%)$} \\
\cline { 2 - 5 } Group & Grade 1t & Grade 2 & Grade 3 & Total \\
\hline A & $10(58 \cdot 84)$ & $6(35 \cdot 28)$ & $1(5 \cdot 88)$ & 17 \\
B & $5(20 \cdot 83)$ & $9(37 \cdot 54)$ & $10(41 \cdot 66)$ & 24 \\
\hline
\end{tabular}

^No patients had chemosis in group C.

tSee text for chemosis grading criteria.

while no patients in the control group $C$ had chemosis. The differences in the incidence in the groups clearly indicate the causative association of the two gentamicin preparations with chemosis and is significant at the 0.001 level using the $\chi^{2}$ test. The difference in the incidence of chemosis between groups $A$ and $B$ indicate an increased incidence of chemosis with the preparation used in group B (with sodium metabisulphite and disodium edetate as preservatives) and is significant $(\mathrm{p}<0.02)$ using the $\chi^{2}$ test.

Table 2 shows the severity of chemosis in patients from groups $A$ and $B$. Of the 17 patients in group $A$ who had chemosis, 10 had grade 1 , six had grade 2 , and one had grade 3 chemosis by the criteria used in this study. Of the 24 patients in group B who had chemosis, five had grade 1, nine had grade 2 and 10 had grade 3 chemosis by the criteria used in this study. Applying the $\chi^{2}$ test the higher number of patients with grades 2 and 3 chemosis in group $B$ is significant $(p<0.02)$. This suggests that the preparation used in group B (with sodium metabisulphite and disodium edetate as preservatives) gives rise to a more severe chemosis compared with the preparation used in group A (preservative free).

\section{Discussion}

Conjunctival chemosis and capillary closure are the reported toxic manifestations of subconjunctival gentamicin. ${ }^{12}$ Fortified topical gentamicin has been shown to cause conjunctival necrosis. ${ }^{4}$ Corneal endothelial changes have been reported after subconjunctival gentamicin in rabbits. ${ }^{5}$

The cause of conjunctival gentamicin toxicity observed remains unclear. The intrinsic cytotoxicity of gentamicin has been demonstrated on kidney proximal tubules,${ }^{6}$ cultured cells obtained from various ocular structures, ${ }^{7}$ and retinal pigment epithelial cells in rabbits. ${ }^{8}$ Similar cytotoxicity has been reported in conjunctival fibroblasts in rats, rabbits, and humans after the subconjunctival injection of gentamicin. ${ }^{9}$ Our results also demonstrate the intrinsic toxicity of gentamicin to the conjunctiva.

Clinical studies ${ }^{12} 10$ raise the possibility of preservatives causing and contributing in the conjunctival toxicity of subconjunctival gentamicin. The gentamicin preparations used in these studies contained two or more of the preservatives sodium metabisulphite, methyl hydroxybenzoate, propyl hydroxybenzoate and disodium edetate. Snider et al have suggested that the preservatives mentioned above may cause or contribute to the toxic effects of gentamicin." Our results clearly demonstrate the causative and contributory role of sodium metabisulphite and disodium edetate in the conjunctival toxicity of subconjunctival gentamicin injection.

The mechanism for the increased conjunctival toxicity of the gentamicin preparation containing sodium metabisulphite and disodium edetate could either be related to a change in the physical properties of the solution induced by these substances or to their intrinsic molecular structure.

An examination of their physical properties however did not reveal any significant difference in $\mathrm{pH}$ between the gentamicin preparation with preservatives ( $\mathrm{pH}$ 3.9) and the preparation without preservatives ( $\mathrm{pH} 4 \cdot 2$ ). The calculated osmolarity of the preservative-free preparation was $67.8 \mathrm{mosm} / \mathrm{l}$ and that of the preparation with preservatives was $143 \mathrm{mosm} / \mathrm{l}$. Considering a solution with an osmolarity of approximately $300 \mathrm{mosm} / 1$ to be isotonic with blood and tears ${ }^{12}$ both the preparations used in this study are significantly hypotonic. Conjunctival chemosis was the major manifestation of gentamicin toxicity indicating a fluid shift out of the conjunctival capillaries. The hypotonicity of both the preparations makes such a fluid shift highly unlikely. This is further substantiated by the fact that the observed relative toxicity of the two preparations is in reverse order to their relative hypotonicity as the preservation-free preparation is more hypotonic than the preparation with preservatives. Thus the $\mathrm{pH}$ and osmolarity changes induced by sodium metabisulphite and disodium edetate can be ruled out as causes of the increased toxicity observed with these substances in this study.

Ocular surface toxicity of various preservatives is well known. Wilson, in a wide ranging study, found significant association of benzalkonium chloride, boric acid, chlorobutanol, edetate, parabens, phenylmercuric nitrate, sodium metabisulphite, and thiomersal with the development of adverse drug reactions after topical ophthalmic therapy. ${ }^{13}$

The two preservatives present in the preparation used in group B patients, sodium metabisulphite and disodium edetate, are used as antioxidant and antioxidant synergist respectively. Sodium metabisulphite is known to cause allergic reactions including anaphylaxis particularly in asthmatics. ${ }^{14}$ Local ocular toxicity of sodium metabisulphite in the form of corneal endothelial cell breakdown leading to corneal oedema has been demonstrated after the intracameral use of adrenaline containing $0 \cdot 1 \%$ sodium metabisulphite in rabbits and monkeys. ${ }^{15}$ Disodium edetate, a chelating agent, has been shown to cause local ${ }^{16}$ as well as systemic $^{17}$ hypocalcaemia. Wilson identified disodium edetate as the most common preservative to be blamed for contact allergy in ocular drug reactions. ${ }^{13}$ 
The choice of antibiotic for prophylaxis in cataract surgery is dependent on the microbial spectrum and its adverse effects. The wide microbial spectrum and reduced toxicity achieved by the use of a preservative-free preparation makes gentamicin an appropriate choice in the prophylaxis of ocular infection after intraocular surgery.

\section{Conclusion}

The preservatives sodium metabisulphite and disodium edetate cause an increase in the frequency and severity of conjunctival toxicity due to subconjunctival gentamicin injection. We therefore recommend the use of preservativefree subconjunctival gentamicin injection for the prophylaxis of ocular infections following intraocular surgery.

We thank Mrs U K Goddard, Mr A K Mathur, Mr S K Datta and Mr J R Innes for their encouragement and permission to use their patients in this study.

1 Pande M. Postoperative conjunctival chemosis in cataract surgery caused by subconjunctival gentamicin injection. Brf Ophthalmol 1991; 75: 660-2.

2 Jenkins CDG, McDonnell PJ, Spalton DJ. Randomised single blind trial to compare the toxicity of subconjunctival gentamicin and cefuroxime in cataract surgery. Brf Ophthalmol 1990; 74: 734-8.
3 Roussel Laboratories Limited. Cidomycin injectable data sheet. In: ABPI Data Sheet Compendium. London: Datapharm Publications, 1990: 1470-1.

4 Davison CR, Tuft SJ, Dart JKG. Conjunctival necrosis after administration of topical fortified aminoglycosides. $A m$ f Ophthalmol 1991; 111: 690-3.

5 Sasamoto K, Akagi Y, Kodama Y, et al. Corneal endothelial changes caused by ophthalmic drugs. Cornea $1984 ; 3: 37-41$.

6 Kozek JC, Mazze RI, Cousins MJ. Nephrotoxicity of gentamicin. Lab Invest 1974; 30: 48.

7 D'Amico DJ, Kenyon KR, Albert DM, et al. Lipid inclusions in human ocular tissues in vitro induced by aminoglycoside in human ocular tissues in vitro induced by aminoglycoside
antibiotics. Birth Defects, Original Article Series 1982; 18: anti

8 D'Amico DJ, Libert J, Kenyon KR, et al. Retinal toxicity of intravitreal gentamicin - an electron microscopy study. Invest Ophthalmol Vis Sci 1984; 25: 564-72.

9 Libert J, Ketalbant-Balasse PE, Van Hoof F, et al. Cellula toxicity of gentamicin. Am $\mathcal{F}$ Ophthalmol 1979; 87: 405-11.

10 Goulstine'DB, Marmion VJ. Subconjunctival gentamicin. BrF Ophthalmol 1971; 55: 478-80.

11 Snider JD, Cohen HB, Chenowith RG. Acute ischaemic retinopathy secondary to intraocular injection of gentamicin. In: Ryan SJ, Dawson AK, Little HL, eds. Retinal diseases. New York: Grune and Stratton, 1985: 227-32.

12 Millimoles and milliequivalents. In: The Pharmaceutical Codex. London: The Pharmaceutical Press, 1979: 570.

13 Wilson FM. Adverse external ocular effects of topical ophthalmic therapy: an epidemiologic, laboratory and ophthalmic therapy: an epidemiologic, laboratory and
clinical study. Trans Am Ophthalmol Soc 1983;81: 854-965.

14 Sodium metabisulphite. In: Reynolds JEF, ed. Martindale The Extra Pharmacopoeia. London: The Pharmaceutical Press, 1989: 1363.

15 Hull DS, Chemotti MT, Edelhauser HF, et al. Effect of epinephrine on the corneal endothelium. Am $\mathcal{F}$ Ophthalmol 1975; 79: 245-50.

16 Caulfield JB, Zir L, Harthorne JW. Blood calcium levels in the presence of arteriographic contrast material. Circulation 1976; 52: 119-23.

17 Berger RE, Gomez LS, Mallette LE. Acute hypocalcemic effects of clinical contrast media injections. Am $\tilde{\mathcal{F}}$ Roentgenol 1982; 138: 283-8. 